\title{
A comparison of the clinicopathological features and prognoses of the classical and the tall cell variant of papillary thyroid cancer: a meta-analysis
}

\author{
Zeming Liu' ${ }^{1, *}$, Wen Zeng ${ }^{2, *}$, Tianwen Chen ${ }^{1}$, Yawen Guo ${ }^{1}$, Chao Zhang ${ }^{3}$, Chunping \\ Liu ${ }^{1, *}$, Tao Huang ${ }^{1, *}$ \\ ${ }^{1}$ Department of Breast and Thyroid Surgery, Union Hospital, Tongji Medical College, Huazhong University of Science and \\ Technology, Wuhan 430022, China \\ ${ }^{2}$ Department of Ophthalmology, Zhongnan Hospital, Wuhan University, Wuhan, Hubei, China \\ ${ }^{3}$ Department of Cardiovascular Surgery, Union Hospital, Tongji Medical College, Huazhong University of Science and \\ Technology, Wuhan, China \\ *These authors contributed equally to this work
}

Correspondence to: Tao Huang, email: huangtaowh@163.com Chunping Liu, email: fac6myt@163.com

Keywords: papillary thyroid carcinoma, tall cell variant, clinicopathological features, mortality risk, meta-analysis

Received: November 01, 2016

Accepted: December 12, 2016

Published: December 21, 2016

\section{ABSTRACT}

Papillary thyroid cancer (PTC) accounts for $80-90 \%$ of all thyroid malignancies. The tall cell variant (TCV) is a rare aggressive histotype of PTC. We performed a metaanalysis to compare the clinicopathological characteristics and prognostic factors of TCV with those of classical papillary thyroid carcinoma (CPTC). A literature search was performed using the PubMed and EMBASE databases using Medical Subject Headings and keywords. Twenty studies that included 1871 patients with TCV and 75323 patients with CPTC were included in our meta-analysis. Odds ratios and confidence intervals were calculated for each study. Patients with TCV were associated with multifocality, higher TNM stage, extrathyroidal extension, vascular invasion, lymph node metastasis, distant metastasis, BRAF mutation, disease-specific survival, and overall survival. We found that TCV cases were associated with more aggressive clinicopathological characteristics and poorer prognoses than CPTC cases were. Our results suggest that TCV is a high-risk PTC that warrants aggressive treatment and follow-up strategies.

\section{INTRODUCTION}

Papillary thyroid cancer (PTC), whose global incidence has rapidly increased in recent decades, accounts for more than $80 \%$ of all thyroid carcinomas, making it the most common type of thyroid malignancy $[1,2]$. PTC is derived from the follicular epithelium [3] and includes many histological variants such as tall cell, columnar cell, diffuse sclerosing, solid, and hobnail $[4,5]$.

The tall cell variant (TCV), a rare histological subtype of PTC that was first reported by Hawk et al. in 1976 [6], constitutes 5 to $11 \%$ of all PTC cases [7]. Kazaure et al. found that TCV incidence increased by $158 \%$ (0.05 per 100000 to 0.13 per 100000$)$ between 2001 and 2008 [8]. Unlike classic PTC (cPTC), TCV tumors comprise obvious rectangular cells, with less colloid, but with nuclear features similar to those observed in cPTC [9]. TCV is usually defined as a PTC in which $30 \%$ or more of tumor cells are twice as long as they are wide; however, the World Health Organization defines PTC as TCV when the tumor is composed predominantly of cells whose heights are at least 3 times their widths [9].

Studies on the clinicopathological characteristics and prognostic outcome of TCV have had controversial results $[10,11]$. No differences were found in some studies between the prognoses of TCV and cPTC, [10] whereas results of other studies and the current American Thyroid Association Guidelines for Differentiated Thyroid Cancer indicate that TCV displays more aggressive pathological characteristics at diagnosis and a poorer prognosis than cPTC does $[1,12]$. Therefore, to resolve these discordant findings, we performed a meta-analysis to compare 
the clinicopathological characteristics at presentation, prognostic factors in terms of cancer-related death, and overall survival in TCV with that in cPTC.

\section{RESULTS}

\section{Literature searches and study features}

The study selection process is described in Figure 1. A total of 264 abstracts and titles were acquired by electronic searches. Of these primary selected abstracts and papers, 167 full-text articles were considered relevant and examined in detail. Following this detailed review, 20 studies that included a total of 1871 patients with TCV and 75323 patients with $\mathrm{cPTC}$ were selected using the described search strategy [8, 10-28]. The major features of the 20 selected studies, which included clinicopathological characteristics and prognostic factors, are summarized in Table 1. Of these 20 studies, 13 evaluated multifocality, 11 evaluated TNM stage, 17 reported on extrathyroidal extension (ETE), 7 evaluated vascular invasion, 19 assessed lymph node metastases (LNM), 10 reported on distant metastases (DM), 4 assessed $B R A F$ mutation, 7 reported diseasespecific survival, and 4 evaluated overall survival. The funnel plots for each outcome indicated no publication bias. Figure 2 shows the funnel plots for ETE (Figure 2A) and LNM (Figure 2B). Egger's linear regression analysis for $\operatorname{ETE}(p=0.181)$ and LNM $(p=0.075)$ revealed no substantial asymmetry.

\section{Meta-analysis of clinicopathological features at diagnosis: TCV vs. cPTC}

Thirteen studies presented clinical data on multifocality (Figure 3A). A fixed-effects model was adopted because heterogeneity was not significant between multifocality and $\operatorname{TCV}\left(P=0.081, I^{2}=37.8 \%\right)$. The OR from the 13 studies was $1.34(95 \% \mathrm{CI}=1.19-1.51)$. Our analysis revealed that the occurrence of multifocality in TCV was significantly higher than that in cPTC $(P<0.001)$.

TNM stage was reported for patients in 11 studies (Figure 3B). A fixed-effects model was adopted because heterogeneity was not significant between TNM stage and TCV $\left(P=0.033, I^{2}=49.1 \%\right)$. The OR from the 11 studies was $3.35(95 \% \mathrm{CI}=2.82-3.99)$. Our analysis revealed that the TNM stage in TCV was significantly higher than that in $\mathrm{cPTC}(P<0.001)$.

Regarding ETE cases, 17 studies were included (Figure 3C). A random-effects model was adopted because heterogeneity was significant between ETE and histology types $\left(P<0.00001, I^{2}=86.9 \%\right)$. According to our analysis, ETE occurred more frequently in patients with TCV than in patients with cPTC. The overall OR was $5.38(95 \% \mathrm{CI}=3.76-7.71, P<0.001)$. We assessed the studies individually by sequentially excluding each of the 17 studies from our meta-analysis. Using this method, we found that $I^{2}$ decreased to $75.4 \%$ when we excluded the study by Michels et al. [18]; therefore, we concluded that the heterogeneity was mainly caused by this particular study (data not shown).

Seven studies presented clinical data on vascular invasion (Figure 4A). A fixed-effects model was adopted, because heterogeneity was not significant between vascular invasion and TCV $\left(P=0.262, I^{2}=22 \%\right)$. The OR from the 12 studies was $2.12(95 \% \mathrm{CI}=1.50-3.00)$. Our analysis revealed that the occurrence of vascular invasion in TCV was significantly higher than that in $\mathrm{cPTC}(P<0.001)$.

LNM stage was reported for patients in 19 studies (Figure 4B). A random-effects model was adopted because heterogeneity was significant between TNM stage and TCV $\left(P=0.003, I^{2}=53.3 \%\right)$. The OR from the 19 studies was $1.85(95 \% \mathrm{CI}=1.54-2.24)$. Our analysis revealed that the occurrence of LNM in TCV was significantly higher than that in cPTC $(P<0.001)$. We assessed the studies individually by sequentially excluding each of the 19 studies from our meta-analysis. Using this method, we found that $I^{2}$ decreased to $41.8 \%$ when we excluded the study by Okuyucu et.al [11], therefore, we concluded that the heterogeneity was mainly caused by this particular study (data not shown).

Regarding DM cases, 10 studies were included (Figure 4C). A random-effects model was adopted because heterogeneity was significant between DM and histology types $\left(P<0.00001, I^{2}=86.7 \%\right)$. According to our analysis, DM occurred significantly more frequently in patients with TCV than in patients with cPTC. The overall OR was 3.10 (95\% CI = 1.61-5.98).

Concerning the presence of $B R A F$ mutation, four studies were included in the meta-analysis (Figure $5 \mathrm{~A}$ ). A fixed-effects model was adopted because heterogeneity was not significant between $B R A F$ mutation and TCV $\left(P=0.131, I^{2}=46.6 \%\right)$. The OR from the 12 studies was $1.86(95 \% \mathrm{CI}=1.06-3.27)$. According to our analysis, the occurrence of $B R A F$ mutation in TCV was significantly higher than that in $\mathrm{cPTC}(P=0.030)$.

\section{Meta-analysis of disease-specific survival and overall survival: TCV vs. cPTC}

Seven studies were included in our meta-analysis of disease-specific survival (Figure 5B). We adopted a random-effects model because the heterogeneity of the data was significant $(P<0.00001)$, and the $I^{2}$ estimate of the variance between the studies was $86.3 \%$. Our analysis showed that disease-specific death was significantly more frequent in patients with TCV than in those with $\mathrm{cPTC}$ $(\mathrm{OR}=5.86,95 \% \mathrm{CI}=3.16-10.87 ; p<0.001)$.

Mortality data were reported in four studies (Figure 5C). A random-effects model was adopted, because the heterogeneity between mortality and histology types was significant $\left(P=0.003, I^{2}=78.4 \%\right)$. Our analysis revealed that the overall mortality in TCV was 
significantly higher than that in cPTC; the overall OR was $3.89(95 \% \mathrm{CI}=1.93-7.88, P<0.001)$.

\section{Subgroup analyses of the effects of TCV on aggressive clinicopathological features and prognostic factors}

We performed subgroup analysis according to the patients' ethnicities in order to investigate ethnicity as a potential source for heterogeneity, and to determine whether the effects of TCV on aggressive clinicopathological features and poor prognosis of PTC were associated with patient ethnicity (Table 2). The effect estimates were broadly consistent among the analyzed subgroups. Heterogeneity was markedly decreased in the subgroup analyses of LNM, but not in the subgroup analyses of ETE, DM, and disease-specific survival.

\section{DISCUSSION}

TCV is usually diagnosed postoperatively on the basis of routine pathology because an accurate preoperative diagnosis is difficult. Classic TCV tumors are "composed of more than $50 \%$ tall cells, a tall cell height at least twice as long as its width, eosinophilic tall cell cytoplasm, and nuclear features characteristic of PTC such as nuclear irregularities, clearing and overlapping, grooves, and pseudoinclusions" [29]. Preoperative sonographic findings indicative of TCV often overlap significantly with those indicative of cPTC, but TCV often harbors features that are more aggressive, such as hypoechogenicity, evidence of ETE, microcalcifications, and macrocalcifications. Therefore, clinicians should consider a TCV diagnosis if such preoperative sonographic findings are present.

Michels et al. reported that TCV was associated with worse prognosis on univariate analysis but not on multivariate analysis [18]. They recommended that TCV should be considered a marker of more aggressive disease but that it was not an independent predictor of prognosis. However, according to Hadiza et al., patients with TCV had worse prognoses than patients with cPTC did, despite receiving relatively more radical treatment such as thyroid surgery and radiotherapy [8]. In our PTC series, patients with TCV displayed more aggressive tumor behavior, including multifocality, higher TNM stage, ETE, vascular invasion, LNM, and DM at diagnosis, and higher diseasespecific mortality and overall mortality rates at follow-up than patients with cPTC did. Therefore, we recommend a more radical treatment strategy and close follow-up of patients with TCV.

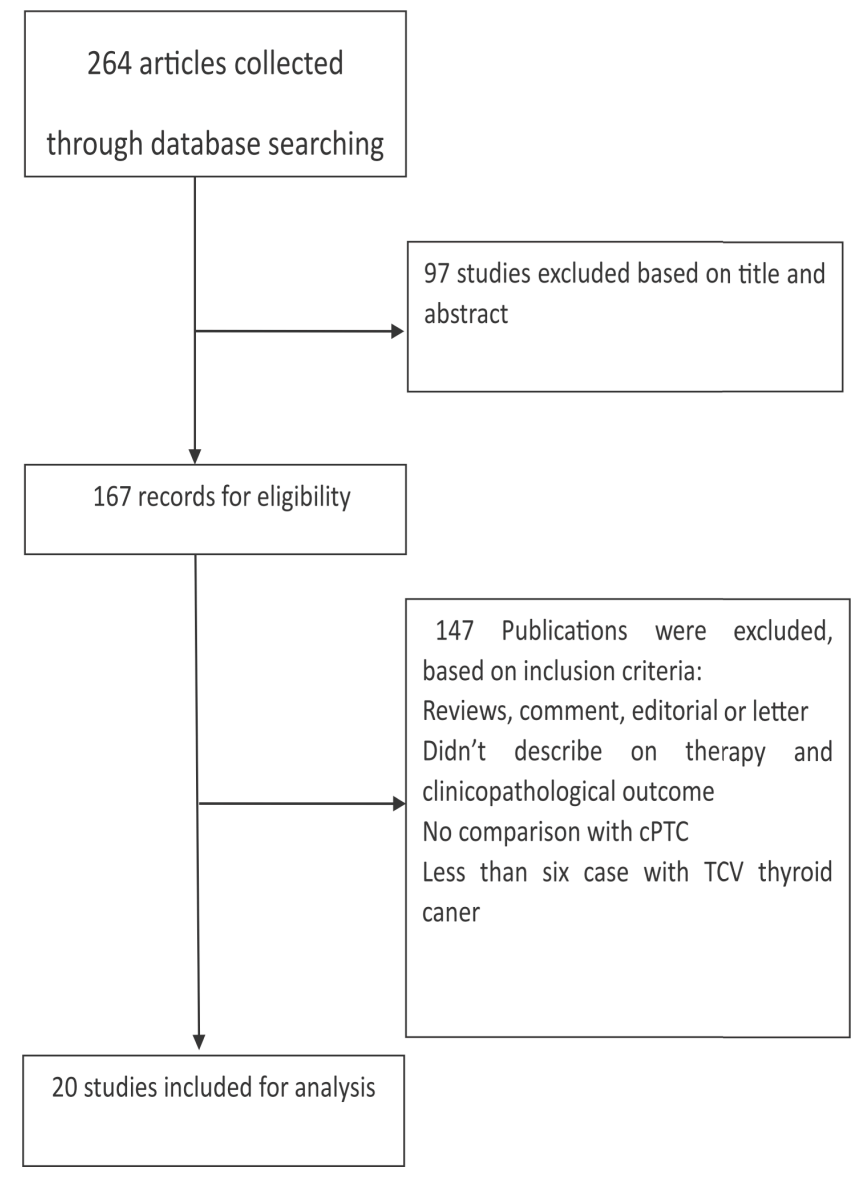

Figure 1: Flow chart showing the process of study selection for the meta-analysis. 


\begin{tabular}{|c|c|c|c|c|c|c|c|c|c|c|}
\hline Study & Year & Country & $\begin{array}{l}\text { Ethnicity (A: } \\
\text { Asians, C: } \\
\text { Caucasians) }\end{array}$ & Study type & $\begin{array}{l}\text { TCV number: } \\
\text { cPTC number }\end{array}$ & $\begin{array}{l}\text { Age }(y) \text { mean } \pm \text { SD or } \\
\text { median (range) }\end{array}$ & Female: Male & $\begin{array}{l}\text { Follow-up, } \\
\text { months }\end{array}$ & $\begin{array}{c}131 \mathrm{I} \text { in } \\
\operatorname{TCV}(\%)\end{array}$ & Poor Outcome \\
\hline Hadiza & 2012 & USA & $\mathrm{C}$ & Retrospective & $573: 42904$ & $55.3(0.7) ; 47.1(0.1)$ & $\begin{array}{c}413: 160 \\
32779: 10125\end{array}$ & $25.2 ; 64.8$ & 56.8 & $\begin{array}{c}\text { Disease-specific survival, } \\
\text { Overall survival }\end{array}$ \\
\hline Eric & 2013 & USA & $\mathrm{C}$ & Retrospective & $97: 18260$ & $49.6(1.4)^{\mathrm{a}} ; 47.6(0.1)$ & $\begin{array}{c}78: 17 \\
15009: 3251\end{array}$ & $45.6 ; 63.3$ & 39.2 & $\begin{array}{l}\text { Disease-specific survival, } \\
\text { Overall survival }\end{array}$ \\
\hline $\mathrm{Oh}$ & 2014 & Korea & A & Retrospective & $95: 203$ & $47.1 ; 47.6$ & $83: 13 ; 164: 39$ & NA & NA & NA \\
\hline Nardone & 2003 & USA & $\mathrm{C}$ & Retrospective & $17: 12$ & $54.1 \pm 14.4 ; 34.3 \pm 11.7$ & $7: 5 ; 10: 7$ & NA & NA & NA \\
\hline Alex & 2008 & China & A & Retrospective & 14:1094 & $53.7(33-81) ; 45.2(7-94)$ & $10: 4 ; 891: 203$ & NA & 92.9 & $\begin{array}{c}\text { Recurrence, cause-specific } \\
\text { survival }\end{array}$ \\
\hline Okuyucu & 2015 & Turkey & $\mathrm{C}$ & Retrospective & $70: 862$ & $49.1 ; 39.9$ & $46: 24 ; 652: 210$ & $146.2 \pm 43.7$ & 100 & Recurrence \\
\hline Lee & 2013 & Korea & A & Retrospective & $13: 202$ & $54.2 ; 44.8$ & $13: 0 ; 160: 42$ & NA & NA & NA \\
\hline Ito & 2008 & Korea & A & Retrospective & $60: 1313$ & NA & $57: 3 ; 1218: 97$ & $154.8 ; 154.8$ & NA & $\begin{array}{l}\text { Disease-free survival, } \\
\text { cause-specific survival }\end{array}$ \\
\hline Michels & 2006 & France & $\mathrm{C}$ & Retrospective & $56: 503$ & $50 ; 45.6$ & $47: 9 ; 416: 87$ & $84 ; 84$ & 67 & Disease-specific survival \\
\hline Ganly & 2014 & USA & $\mathrm{C}$ & Retrospective & $134: 288$ & NA & $89: 45 ; 211: 77$ & $112 ; 112$ & 74 & $\begin{array}{l}\text { Disease-specific survival, } \\
\text { recurrence-free survival }\end{array}$ \\
\hline Prendiville & 2000 & USA & $\mathrm{C}$ & Retrospective & 20:1355 & $49.6 ; 35.7$ & NA & $45.6 ; 189.6$ & NA & Cancer-related mortality \\
\hline Bernstein & 2013 & USA & $\mathrm{C}$ & Retrospective & $27: 26$ & 56 ; NA & $24: 2 ; 22: 5$ & $20 ; 20$ & 69.2 & Disease-free survival \\
\hline Morris & 2010 & USA & $\mathrm{C}$ & Retrospective & $278: 2522$ & $54.3 ; 46.3$ & $207: 71 ; 1864: 658$ & $28.0 ; 26.1$ & 55.0 & Disease-specific survival \\
\hline Axelsson & 2014 & Iceland & $\mathrm{C}$ & Retrospective & $49: 327$ & $66 ; 49$ & $29: 20 ; 258: 69$ & $92.4 ; 130.8$ & NA & $\begin{array}{l}\text { Disease-specific survival, } \\
\text { Overall survival }\end{array}$ \\
\hline Ghossein & 2007 & USA & $\mathrm{C}$ & Retrospective & $62: 83$ & $41 ; 39$ & $51: 11 ; 65: 18$ & $33.6 ; 36$ & 63.3 & Recurrence \\
\hline Beninato & 2013 & USA & $\mathrm{C}$ & Retrospective & $59: 58$ & $45.1 \pm 13.7 ; 44.9 \pm 13.9$ & $44: 15 ; 47: 11$ & $30 ; 20$ & 93 & Recurrence \\
\hline Machens & 2004 & Germany & $\mathrm{C}$ & Retrospective & $16: 316$ & $57 ; 46$ & $10: 6 ; 231: 85$ & NA & NA & NA \\
\hline Regalbuto & 2013 & NA & $\mathrm{C}$ & Retrospective & $30: 293$ & $50.6 \pm 12.8 ; 47.3 \pm 13.2$ & $25: 5 ; 250: 43$ & $89 ; 89$ & NA & $\begin{array}{l}\text { Persistent or recurrent } \\
\text { disease }\end{array}$ \\
\hline Min & 2013 & Korea & A & Retrospective & $23: 303$ & $47.8 ; 55.1$ & $20: 3 ; 249: 54$ & $33.1 ; 33.1$ & NA & NA \\
\hline Shi & 2016 & USA & $\mathrm{C}$ & Retrospective & $239: 4702$ & $51(39-64) 43(33-55)$ & $\begin{array}{c}174: 65 \\
3584: 1118\end{array}$ & 37.0 & 89.1 & $\begin{array}{c}\text { Recurrence, Overall } \\
\text { survival }\end{array}$ \\
\hline
\end{tabular}

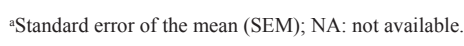

The interest in molecular analysis of PTC has been growing for both diagnostic and prognostic reasons [30]. Molecular analysis typically involves a BRAF (V600E) mutation, which has emerged as a marker of aggressive behavior in thyroid cancer and is associated with clinical progression and recurrence of PTC [3]. The prevalence of $B R A F$ mutation rates in TCV vary across reports. Several authors have reported a high prevalence of $B R A F$ mutations in $\mathrm{TCV}$, while others have reported a low prevalence $[7$, $10,12,16,31]$. In the present study, we demonstrated that $B R A F$ mutations were associated with TCV. These discrepant findings may be because $B R A F$ mutations occur in early stages of tumorigenesis and are associated with specific morphology and aggressive characteristics.

It is unknown whether aggressive tumor behavior is associated with the other molecular profiles of TCV. Some studies have indicated that molecular factors intrinsic to TCV are responsible for its aggressive biologic and clinical features [32]. For example, Wreesmann et al. and Campo et al. illustrated that the high prevalence of Muc1 and type IV collagenase expression may result in degradation of stroma and greater invasive properties in TCV compared to those in cPTC and its follicular variant [33, 34].

$\mathrm{TCV}$ cases that were treated with total thyroidectomy and accessorial radioactive iodine (RAI) therapy had better survival rates than cases with lower rates of surgical resection and no RAI therapy did [9]. However, Ghossein and Livolsi found that TCV is overrepresented in fluorodeoxyglucose positron-emission tomogram (FDG-PET)-positive thyroid carcinomas that are refractory to RAI therapy, which may due to a high prevalence of $B R A F$ somatic mutations in patients with TCV [35]. Furthermore, Rivera et al. found that $20 \%$ of FDG-PET-positive/RAI therapy-refractory tumors are TCV tumors [36]. Therefore, more studies are needed to differentiate TCVs that are refractory to RAI therapy, and to develop effective targeted therapies against these otherwise incurable carcinomas.

A major limitation of this meta-analysis is the potential heterogeneity caused by differences in disease management practices, pathology reporting, follow-up duration, and the definition of remission, which may have 
Table 2: Subgroup analysis according to patient ethnicity of the effects of the tall cell variant on the aggressive clinicopathological features and poor prognosis of papillary thyroid cancer

\begin{tabular}{lcccc}
\hline \multicolumn{1}{c}{ Subgroup } & Odds ratio & $\mathbf{9 5 \%}$ confidence interval & $\left.\boldsymbol{I}^{\mathbf{2}} \mathbf{\%}\right)$ & Model used \\
\hline $\begin{array}{l}\text { Extrathyroidal extension } \\
\text { Asians }\end{array}$ & 5.17 & {$[3.24,8.25]$} & 0 & Fixed-effects \\
$\begin{array}{l}(3 \text { studies }) \\
\text { Caucasians } \\
(14 \text { studies })\end{array}$ & 5.51 & {$[3.67,8.28]$} & 89.3 & Random-effects \\
$\begin{array}{l}\text { Lymph node metastases } \\
\text { Asians } \\
(6 \text { studies })\end{array}$ & 2.55 & {$[1.91,3.39]$} & 21.6 & Fixed-effects \\
$\begin{array}{l}\text { Caucasians } \\
(13 \text { studies })\end{array}$ & 1.64 & {$[1.37,1.98]$} & 43.6 & Random-effects \\
$\begin{array}{l}\text { Distant metastasis } \\
\text { Asians } \\
(2 \text { studies })\end{array}$ & & & & \\
$\begin{array}{l}\text { Caucasians } \\
(8 \text { studies })\end{array}$ & 1.74 & {$[0.41,7.41]$} & 0 & Fixed-effects \\
$\begin{array}{l}\text { Disease-specific survival } \\
\text { Asians } \\
(1 \text { study) }\end{array}$ & 3.36 & {$[1.64,6.89]$} & 89.6 & Random-effects \\
$\begin{array}{l}\text { Caucasians } \\
(6 \text { studies })\end{array}$ & & & & \\
\hline
\end{tabular}

affected the study conclusions. Another limitation is the small number of included articles and the unavailability of relevant unpublished data for further analysis. Therefore, larger studies would help address the role of TCV in the worsening of PTC prognosis in a more definite manner.
The present meta-analysis demonstrated that patients with TCV, an aggressive variant of PTC, present with more unfavorable features at diagnosis, such as multifocality, higher TNM stage, ETE, vascular invasion, LNM, DM, and BRAF mutations. Higher disease-specific

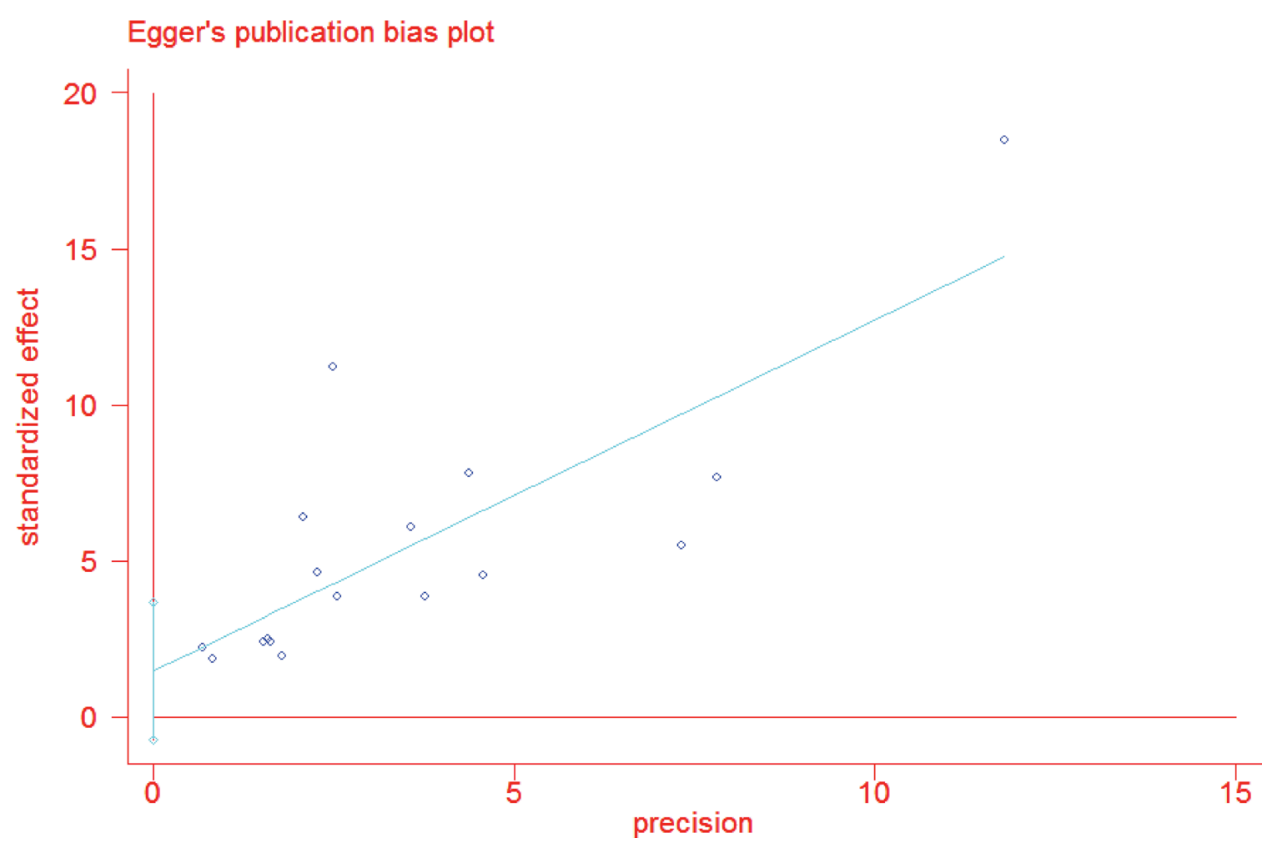

Figure 2: Funnel plots for publication bias considering both extrathyroidal extension. 


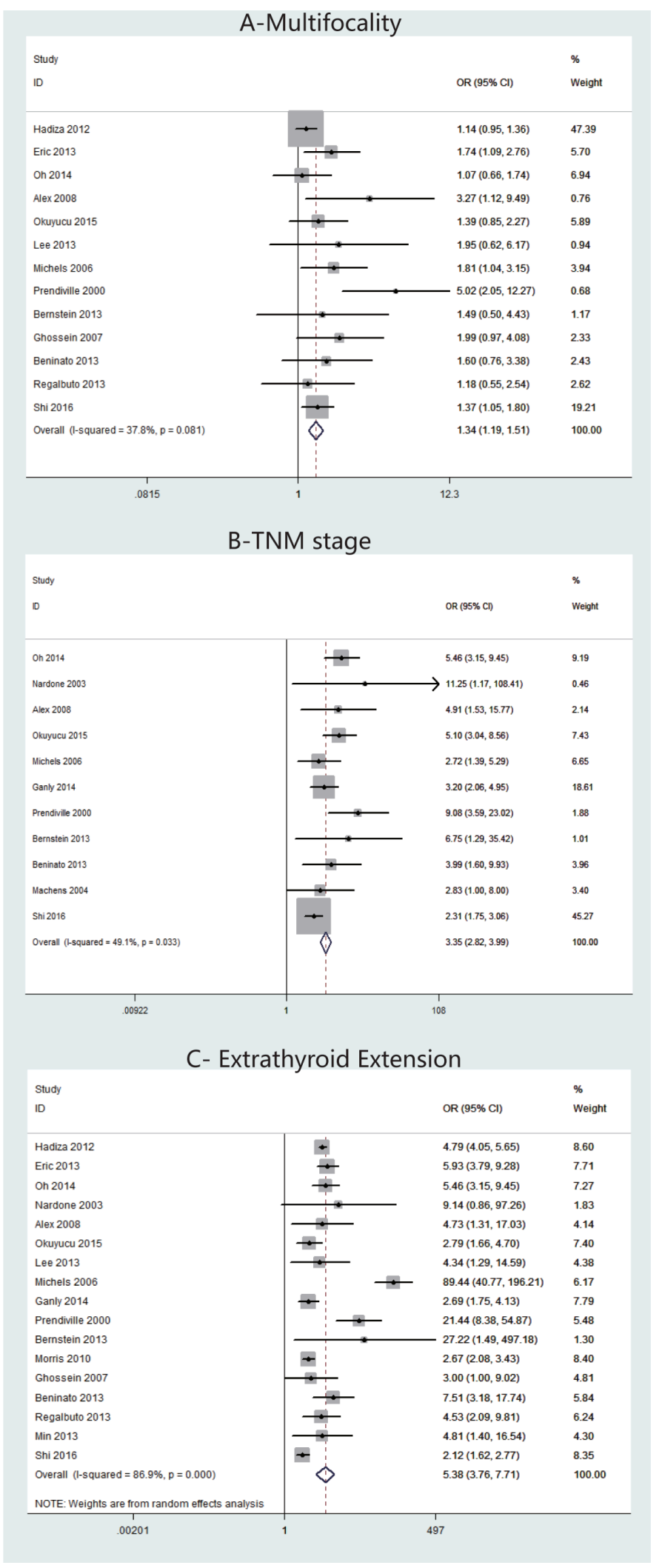

Figure 3: Forest plots of odds ratios (ORs) for multifocality (Panel A), TNM stage (Panel B) and extrathyroidal extension (Panel C) associated with the tall cell variant (TCV) vs classic papillary thyroid cancer (cPTC). Each study is represented as a square and a horizontal line: the area of the square reflects the weight of the study in the meta-analysis, while the line represents the OR with its confidence interval. Diamonds represent the pooled ORs and their confidence interval. 


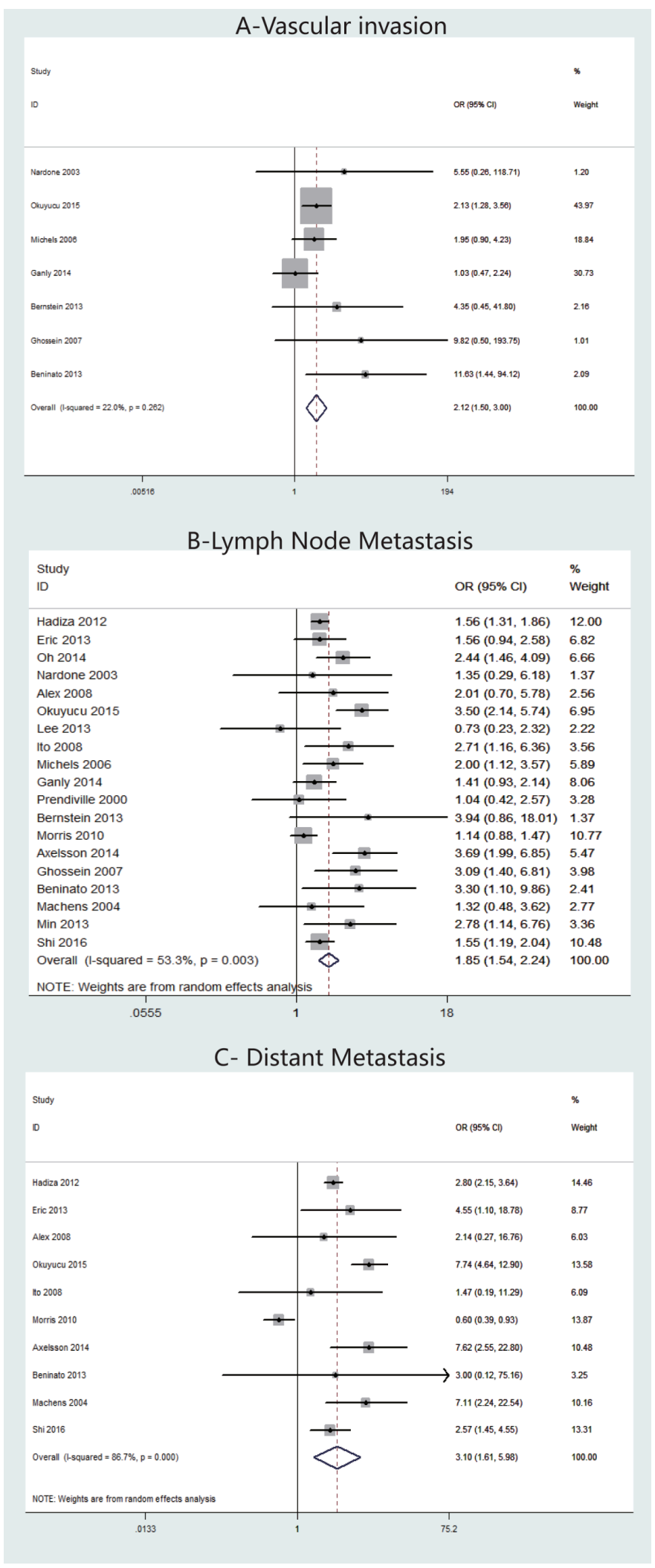

Figure 4: Forest plots of odds ratios (ORs) for vascular invasion (Panel A), lymph node metastasis (Panel B) and distant metastasis (Panel C) associated with the tall cell variant (TCV) vs classic papillary thyroid cancer (cPTC). Each study is represented as a square and a horizontal line: the area of the square reflects the weight of the study in the meta-analysis, while the line represents the OR with its confidence interval. Diamonds represent the pooled ORs and their confidence interval. 


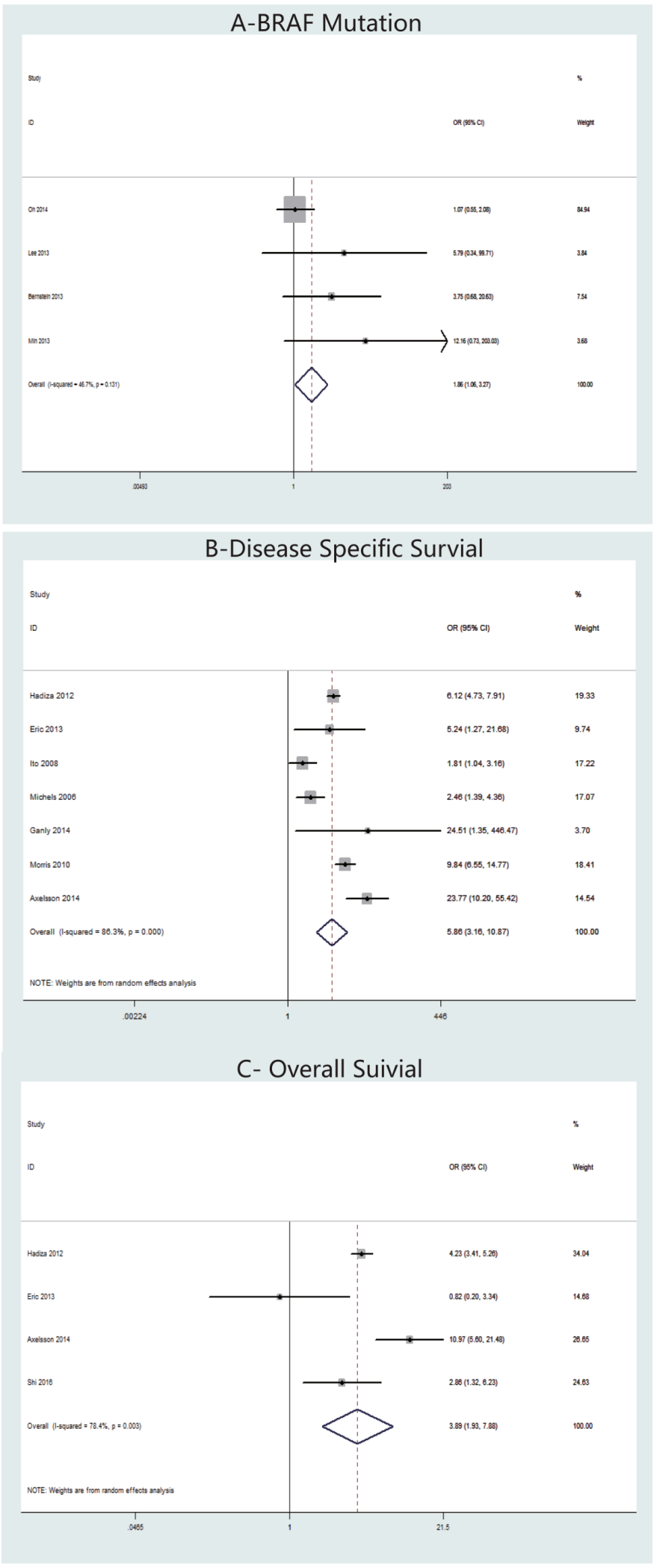

Figure 5: Forest plots of odds ratios (ORs) for BRAF mutation (Panel A), disease-specific survival (Panel B) and overall survival (Panel C) associated with the tall cell variant (TCV) vs classic papillary thyroid cancer (cPTC). Each study is represented as a square and a horizontal line: the area of the square reflects the weight of the study in the meta-analysis, while the line represents the OR with its confidence interval. Diamonds represent the pooled ORs and their confidence interval. 
mortality and overall mortality rates are found during follow-up in these patients than in patients with cPTC. The results of our meta-analysis demonstrate that TCV should be considered a high-risk PTC and that aggressive treatment and follow-up strategies should be adopted in these cases.

\section{MATERIALS AND METHODS}

\section{Search strategy and literature selection}

A systematical literature search was performed using online electronic databases (PubMed, EMBASE, and ISI Web of Science) for published papers through September 30, 2016, and the search was supplemented by manual searching and reference backtracking using the following Medical Subject Headings and keywords: "tall cell variant", "TCV", "thyroid," "neoplasm(s)," "tumor," "cancer," and "carcinoma". Relevant unpublished data that were presented at international meetings such as the American Thyroid Association meeting were also included. We contacted the authors for additional tabular data when necessary. The searches were limited to studies conducted in humans and written in English. Furthermore, the reference lists of retrieved articles were also reviewed to identify additional studies.

The following criteria were applied into the literature selection for studies that examined the association of TCV with high-risk clinic pathological factors and prognostic outcomes: (1) the studies had a randomized controlled trial or retrospective comparative study (cohort or casecontrol study) design; (2) the studies compared the TCV and cPTC groups of patients; (3) the study investigated at least one outcome of interest; and (4) weighted mean differences (WMDs) and ORs with 95\% CIs were reported or were available to be calculated. Studies lacking a control population, duplicates of previous publication, animal studies, abstracts, single-case reports, and reviews were excluded. For studies with the same or overlapping data published by the same investigators, we selected studies with complete designs and larger sample sizes in our meta-analysis.

\section{Data extraction}

All data were extracted independently by two authors (ZM Liu and W Zeng) and cross-checked to resolve any discrepancies. The following information regarding the association of TCV with clinicopathological risk factors, disease-related mortality, and overall mortality of PTC was extracted from each included study: first author, publication year, study location, ethnicity, number of TCV cases, age, female:male ratio in both TCV and cPTC groups, and the incidence rate of clinicopathological features, RAI therapy, and poorer outcome, in both TCV and cPTC groups.
The following outcomes were extracted for patients with primary PTC in order to compare the TCV and cPTC groups: the presence of ETE, larger tumor size, multifocality, LNM, DM, stage, vascular invasion, disease-specific survival, and overall mortality. All procedures conformed to the guidelines for the metaanalysis of observational studies in epidemiology [37].

\section{Statistical analysis}

The summary ORs with 95\% CIs and weighted mean differences with $95 \%$ CIs were calculated to compare dichotomous and continuous variables, respectively. The $\chi^{2}-$ based Cochran's Q statistic test and $I^{2}$ statistics were used to evaluate heterogeneity between the studies. Heterogeneity was considered significant when $P$ was $<0.1$ for the Q statistic or for an $I^{2}$ statistic $>50 \%$ [38]. A fixed-effects model (Mantel-Haenszel method) was used when no significant heterogeneity was detected; otherwise, a randomeffects model (DerSimonian-Laird method) was applied. Subgroup analyses were also performed according to patient ethnicity. In addition, we performed sensitivity analysis to assess the influence of each study on the overall estimate. Moreover, the potential publication bias was assessed using Egger's test and funnel plot analysis. All analyses were conducted using Stata (version 13.1; StataCorp LP, College Station, TX, USA). The $P$-values were two-tailed with the level of significance set at 0.05 .

\section{CONFLICTS OF INTEREST}

The authors declare no conflicts of interest.

\section{Authors' contributions}

All authors contributed to the design of the study and writing of the manuscript Z. M. L and W. Z undertook the research and performed the analyses. All authors reviewed and approved the final version of the manuscript.

\section{REFERENCES}

1. Haugen BR, Alexander EK, Bible KC, Doherty GM, Mandel SJ, Nikiforov YE, Pacini F, Randolph GW, Sawka AM, Schlumberger M, Schuff KG, Sherman SI, Sosa JA, et al. 2015 American Thyroid Association Management Guidelines for Adult Patients with Thyroid Nodules and Differentiated Thyroid Cancer: The American Thyroid Association Guidelines Task Force on Thyroid Nodules and Differentiated Thyroid Cancer. Thyroid . 2016; 26:1-133.

2. Chen W, Zheng R, Baade PD, Zhang S, Zeng H, Bray F, Jemal A, Yu XQ, He J. CA Cancer J Clin. 2015. CA: a cancer journal for clinicians. 2016; 66:115-132.

3. Xing M. Molecular pathogenesis and mechanisms of thyroid cancer. Nature reviews Cancer. 2013; 13:184-199. 
4. Wang X, Cheng W, Liu C, Li J. Tall cell variant of papillary thyroid carcinoma: current evidence on clinicopathologic features and molecular biology. Oncotarget. 2016; 7:40792-40799. doi: $10.18632 /$ oncotarget.8215.

5. Koo JS, Hong S, Park CS. Diffuse sclerosing variant is a major subtype of papillary thyroid carcinoma in the young. Thyroid. 2009; 19:1225-1231.

6. Hawk WA, Hazard JB. The many appearances of papillary carcinoma of the thyroid. Cleveland Clinic quarterly. 1976; 43:207-215.

7. Silver CE, Owen RP, Rodrigo JP, Rinaldo A, Devaney KO, Ferlito A. Aggressive variants of papillary thyroid carcinoma. Head \& neck. 2011; 33:1052-1059.

8. Kazaure HS, Roman SA, Sosa JA. Aggressive variants of papillary thyroid cancer: incidence, characteristics and predictors of survival among 43,738 patients. Annals of surgical oncology. 2012; 19:1874-1880

9. Roman S, Sosa JA. Aggressive variants of papillary thyroid cancer. Current opinion in oncology. 2013; 25:33-38.

10. Oh WJ, Lee YS, Cho U, Bae JS, Lee S, Kim MH, Lim DJ, Park GS, Lee YS, Jung CK. Classic papillary thyroid carcinoma with tall cell features and tall cell variant have similar clinicopathologic features. Korean journal of pathology. 2014; 48:201-208.

11. Okuyucu K, Alagoz E, Arslan N, Emer O, Ince S, Deveci S, Ayan A, Taslipinar A, Gunalp B, Azal O. Clinicopathologic features and prognostic factors of tall cell variant of papillary thyroid carcinoma: comparison with classic variant of papillary thyroid carcinoma. Nuclear medicine communications. 2015; 36:1021-1025.

12. Bernstein J, Virk RK, Hui P, Prasad A, Westra WH, Tallini G, Adeniran AJ, Udelsman R, Sasaki CT, Roman SA, Sosa JA, Prasad ML. Tall cell variant of papillary thyroid microcarcinoma: clinicopathologic features with BRAF(V600E) mutational analysis. Thyroid. 2013; 23:1525-1531.

13. Kuo EJ, Goffredo P, Sosa JA, Roman SA. Aggressive variants of papillary thyroid microcarcinoma are associated with extrathyroidal spread and lymph-node metastases: a population-level analysis. Thyroid. 2013; 23:1305-1311.

14. Nardone HC, Ziober AF, LiVolsi VA, Mandel SJ, Baloch ZW, Weber RS, Mick R, Ziober BL. c-Met expression in tall cell variant papillary carcinoma of the thyroid. Cancer. 2003; 98:1386-1393.

15. Leung AK, Chow SM, Law SC. Clinical features and outcome of the tall cell variant of papillary thyroid carcinoma. The Laryngoscope. 2008; 118:32-38.

16. Lee SH, Jung CK, Bae JS, Jung SL, Choi YJ, Kang CS. Liquid-based cytology improves preoperative diagnostic accuracy of the tall cell variant of papillary thyroid carcinoma. Diagnostic cytopathology. 2014; 42:11-17.

17. Ito $\mathrm{Y}$, Hirokawa M, Uruno T, Kihara M, Higashiyama T, Takamura Y, Miya A, Kobayashi K, Matsuzuka F, Miyauchi A. Prevalence and biological behaviour of variants of papillary thyroid carcinoma: experience at a single institute. Pathology. 2008; 40:617-622.

18. Michels JJ, Jacques M, Henry-Amar M, Bardet S. Prevalence and prognostic significance of tall cell variant of papillary thyroid carcinoma. Human pathology. 2007; 38:212-219.

19. Ganly I, Ibrahimpasic T, Rivera M, Nixon I, Palmer F, Patel SG, Tuttle RM, Shah JP, Ghossein R. Prognostic implications of papillary thyroid carcinoma with tall-cell features. Thyroid. 2014; 24:662-670.

20. Prendiville S, Burman KD, Ringel MD, Shmookler BM, Deeb ZE, Wolfe K, Azumi N, Wartofsky L, Sessions RB. Tall cell variant: an aggressive form of papillary thyroid carcinoma. Otolaryngol Head Neck Surg. 2000; 122:352-357.

21. Morris LG, Shaha AR, Tuttle RM, Sikora AG, Ganly I. Tallcell variant of papillary thyroid carcinoma: a matched-pair analysis of survival. Thyroid. 2010; 20:153-158.

22. Ghossein RA, Leboeuf R, Patel KN, Rivera M, Katabi N, Carlson DL, Tallini G, Shaha A, Singh B, Tuttle RM. Tall cell variant of papillary thyroid carcinoma without extrathyroid extension: biologic behavior and clinical implications. Thyroid. 2007; 17:655-661.

23. Axelsson TA, Hrafnkelsson J, Olafsdottir EJ, Jonasson JG. Tall cell variant of papillary thyroid carcinoma: a populationbased study in Iceland. Thyroid. 2015; 25:216-220.

24. Machens A, Holzhausen HJ, Lautenschlager C, Dralle H. The tall-cell variant of papillary thyroid carcinoma: a multivariate analysis of clinical risk factors. Langenbeck's archives of surgery. 2004; 389:278-282.

25. Beninato $\mathrm{T}$, Scognamiglio $\mathrm{T}$, Kleiman DA, Uccelli A, Vaca D, Fahey TJ, 3rd and Zarnegar R. Ten percent tall cells confer the aggressive features of the tall cell variant of papillary thyroid carcinoma. Surgery. 2013; 154:1331-1336; discussion 1336.

26. Regalbuto C, Malandrino P, Frasca F, Pellegriti G, Le Moli R, Vigneri R, Pezzino V. The tall cell variant of papillary thyroid carcinoma: clinical and pathological features and outcomes. Journal of endocrinological investigation. 2013; 36:249-254.

27. Min HS, Lee C, Jung KC. Correlation of Immunohistochemical Markers and BRAF Mutation Status with Histological Variants of Papillary Thyroid Carcinoma in the Korean Population. Journal of Korean Medical Science. 2013; 28:534.

28. Shi X, Liu R, Basolo F, Giannini R, Shen X, Teng D, Guan H, Shan Z, Teng W, Musholt TJ, Al-Kuraya K, Fugazzola L, Colombo C, et al. Differential Clinicopathological Risk and Prognosis of Major Papillary Thyroid Cancer Variants. The Journal of clinical endocrinology and metabolism. 2016; 101:264-274.

29. Choi YJ, Shin JH, Kim JH, Jung SL, Son EJ, Oh YL. Tall cell variant of papillary thyroid carcinoma: sonographic and clinical findings. Journal of ultrasound in medicine. 2011; 30:853-858.

30. Liu R, Bishop J, Zhu G, Zhang T, Ladenson PW, Xing M. Mortality Risk Stratification by Combining BRAF V600E, 
TERT Promoter Mutations in Papillary Thyroid Cancer: Genetic Duet of BRAF, TERT Promoter Mutations in Thyroid Cancer Mortality. JAMA oncology. 2016.

31. Lloyd RV, Buehler D, Khanafshar E. Papillary thyroid carcinoma variants. Head and neck pathology. 2011; 5:51-56.

32. LiVolsi VA. Papillary carcinoma tall cell variant (TCV): a review. Endocrine pathology. 2010; 21:12-15.

33. Wreesmann VB, Sieczka EM, Socci ND, Hezel M, Belbin TJ, Childs G, Patel SG, Patel KN, Tallini G, Prystowsky M, Shaha AR, Kraus D, Shah JP, et al. Genomewide profiling of papillary thyroid cancer identifies MUC1 as an independent prognostic marker. Cancer research. 2004; 64:3780-3789.

34. Campo E, Merino MJ, Liotta L, Neumann R, StetlerStevenson W. Distribution of the 72-kd type IV collagenase in nonneoplastic and neoplastic thyroid tissue. Human pathology. 1992; 23:1395-1401.
35. Ghossein R, Livolsi VA. Papillary thyroid carcinoma tall cell variant. Thyroid. 2008; 18:1179-1181.

36. Rivera M, Ghossein RA, Schoder H, Gomez D, Larson SM, Tuttle RM. Histopathologic characterization of radioactive iodine-refractory fluorodeoxyglucose-positron emission tomography-positive thyroid carcinoma. Cancer. 2008; 113:48-56.

37. Stroup DF, Berlin JA, Morton SC, Olkin I, Williamson GD, Rennie D, Moher D, Becker BJ, Sipe TA, Thacker SB. Meta-analysis of observational studies in epidemiology: a proposal for reporting. Meta-analysis Of Observational Studies in Epidemiology (MOOSE) group. Jama. 2000; 283:2008-2012.

38. Higgins JP, Thompson SG, Deeks JJ, Altman DG. Measuring inconsistency in meta-analyses. BMJ (Clinical research ed). 2003; 327:557-560. 